\title{
Mechanism of the Oxidation of Methyl $n$-Propyl Ketone by Manganese (III) Sulphate
}

\author{
K. K. BANerJi, P. NATH, and G. V. Bakore * \\ Department of Chemistry, University of Jodhpur, Jodhpur (India) \\ (Z. Naturforsch. 26 b, 318-319 [1971] ; received December 7, 1970)
}

\begin{abstract}
The oxidation of methyl $n$-propyl ketone by $\mathrm{Mn}$ (III) sulphate in aqueous acetic acid is first order with respect to the ketone and $\mathrm{Mn}$ (III). The rate independent of acidity and solvent composition. Added Mn(II) does not alter the rate. The activation parameters for the oxidation and enolisation reactions were evaluated. The oxidation is faster than the enolisation under similar conditions. A mechanism involving an attack on the keto-form by $\mathrm{Mn}$ (III) sulphate complex is proposed.
\end{abstract}

Manganese (III) pyrophosphate oxidises cyclohexanone at a rate equal to the rate of enolisation and this supports the belief that ketones are oxidised via their enol form ${ }^{1}$. LITTLER ${ }^{2}$, however, observed that manganese (III) sulphate oxidises cyclohexanone at a rate faster than its enolisation and concluded that the keto-form is directly attacked. Recently we have shown that the oxidation of acetone also involve attack on the keto form ${ }^{3}$. The results of methyl $n$-propyl ketone-Mn(III) reaction are presented here.

\section{Results}

Product Analysis: The completely reduced reaction mixture gives a red-brown colour with ninhydrin in the presence of strong sulphuric acid. This indicate that propionaldehyde is the main oxidation product ${ }^{4}$.

Rate-laws: When the concentration of the ketone is in excess, the rate at which $\mathrm{Mn}$ (III) disappears follows first order rate laws. Further the first order rate constant is independent of initial concentration of the oxidant (Table I). The oxidation rate varies linearly with the concentration of ketone (Table II). Variation in the concentration of sulphuric acid, at constant ionic strength, does not appreciably affect the rate oxidation (Table III).

Addition of $\mathrm{Mn}(\mathrm{II})$ sulphate $(0.05-0.5 \mathrm{M})$ has no effect on the oxidation rate. Similarly changes in

Reprints request to Dr. K. K. BANERJI, Department of Chemistry, University of Jodhpur, Jodhpur, Indian.

* Present address: Department of Chemisary, University of Udaipur, Udaipur (India).

1 A. Y. Drummond and W. A. Waters, J. chem. Soc. [London] 1955, 397 . $\begin{array}{llllllc}10^{3}[\mathrm{Mn}(\mathrm{III})] \mathrm{mol} l^{-1} & 2.19 & 3.28 & 4.38 & 6.56 & 8.75 & 10.8 \\ 10^{4} k_{1}\left(\mathrm{sec}^{-1}\right) & 1.33 & 1.44 & 1.44 & 1.54 & 1.33 & 1.44\end{array}$

Table I. Oxidant dependence of reaction rate [Ketone] : 4.6. $\times 10^{-2} \mathrm{M}^{2}\left[\mathrm{H}_{2} \mathrm{SO}_{4}\right] 4.0 \mathrm{M}[\mathrm{Mn}(\mathrm{II})] 0.22 \mathrm{M}$.

\begin{tabular}{lcccccc}
\hline $10^{2}\left[\right.$ Ketone] mol $^{-1}$ & 2.31 & 4.62 & 9.24 & 11.5 & 13.9 & 18.5 \\
$10^{5} k_{1}\left(\mathrm{sec}^{-1}\right)$ & 7.20 & 14.4 & 28.9 & 36.0 & 43.3 & 57.8 \\
$10^{3} k_{1} /[$ Ketone] & 3.12 & 3.12 & 3.12 & 3.13 & 3.11 & 3.12
\end{tabular}

Table II. Substrate dependence of reaction rate [Mn(III) ] $\left.4.28 \times 10^{-3} \mathrm{M}^{2} \mathrm{H}_{2} \mathrm{SO}_{4}\right] 2.0 \mathrm{M}[\mathrm{Mn}$ (II) $] 0.21 \mathrm{M}$.

\begin{tabular}{lllllll}
\hline$\left[\mathrm{H}_{2} \mathrm{SO}_{4}\right] \mathrm{mol} l^{-1}$ & 2.0 & 2.5 & 3.0 & 3.5 & 4.0 & 5.0 \\
$10^{4} k_{1}\left(\mathrm{sec}^{-1}\right)$ & 1.44 & 1.60 & 1.44 & 1.20 & 1.44 & 1.20
\end{tabular}

Table III. Acidity dependence of reaction rate [Ketone] $4.62 \times 10^{-2} \mathrm{M}[\mathrm{Mn}(\mathrm{III})] 4.28 \times 10^{-3} \mathrm{M}[\mathrm{Mn}(\mathrm{II})] 0.11 \mathrm{M}$ $\left[\mathrm{H}_{2} \mathrm{SO}_{4}+\mathrm{NaHSO}_{4}\right] 5.0 \mathrm{M}$.

\begin{tabular}{lrrrrr}
\hline Acetic acid [\%] & 20 & 30 & 40 & 50 & 60 \\
$10^{4} k_{1}\left(\mathrm{sec}^{-1}\right)$ & 1.44 & 1.44 & 1.20 & 1.80 & 1.65 \\
\hline
\end{tabular}

Table IV. Solvent composition dependence of reaction rate [Ketone] $4.6 \times 10^{-2} \mathrm{M}$ [Mn(III) ] $4.3 \times 10^{-3} \mathrm{M}$ [Mn(II) ] $0.11 \mathrm{M}\left[\mathrm{H}_{2} \mathrm{SO}_{4}\right] 2.0 \mathrm{M}$.

\begin{tabular}{lllllll}
\hline Temp. $\left[{ }^{\circ} \mathrm{C}\right]$ & 30 & 35 & 40 & 45 & $\begin{array}{c}\Delta H^{*} \\
\left(\mathrm{kcal} \cdot \mathrm{mol}^{-1}\right)\end{array}$ \\
\hline $10^{3} k$ & & & & &
\end{tabular}

Table V. Effect of temperature [Mn(III)] $4.28 \times 10^{-3} \mathrm{M}$ $[\mathrm{Mn}(\mathrm{II})] 0.21 \mathrm{M}\left[\mathrm{H}_{2} \mathrm{SO}_{4}\right] 2.0 \mathrm{M}$.

2 J. S. Littlen, J. chem. Soc. [London] 1962, 832.

3 K. K. BanerJi, P. Nath, and G. V. Bakore, Indian J. Chem. 8, 337 [1970].

${ }^{4}$ F. FEIGL, "Spot tests in organic analysis", Elsevier, Amsterdam 1966, p. 591. 
proportions of acetic acid in the solvent mixture has no effect (Table IV).

Effect of temperature: Data in Table V summarize the effect of temperature on the rate of oxidation. The specific rate constant, $k$, is obtained from the relation, $k=k_{1} /$ [ketone]. A plot of $\log k$ against inverse of temperature gave a straight line. Arrhenius equation is, therefore, valid for this reaction. The activation parameters are calculated in the usual manner.

Rate of Enolisation: The rates of enolisation were measured by bromination method. The bromination of methyl $n$-propyl ketone is first order with respect to each the ketone and hydrogen ions but zero order to bromine. The rate of bromination increases with proportion of acetic acid in the solvent mixture (Table VI). The rates of bromination were obtained at different temperatures and activation parameters calculated (Table VII).

\begin{tabular}{lcccl}
\hline Acetic acid [\%] & 20 & 30 & 50 & 80 \\
$10^{4} k_{2}\left(l \mathrm{~mol}^{-1} \mathrm{sec}^{-1}\right)$ & 3.31 & 3.96 & 5.20 & 11.1 \\
\hline
\end{tabular}

Table VI. Rate of bromination. Temp. $35^{\circ} \mathrm{C}$.

\begin{tabular}{llllll}
\hline Temp. $\left[{ }^{\circ} \mathrm{C}\right]$ & 30 & 35 & 40 & $\begin{array}{c}\Delta H^{*} \\
{\left[\mathrm{kcal} \cdot \mathrm{mol}^{-1}\right]}\end{array}$ & $\begin{array}{c}\Delta S^{*} \\
(\mathrm{e} . u .)\end{array}$ \\
\hline $10^{4} k_{2}\left(l \mathrm{~mol}^{-1} \mathrm{sec}^{-1}\right)$ & 2.88 & 4.00 & 6.76 & 20.5 & -8.1 \\
\hline
\end{tabular}

Table VII. Effect of temperature on bromination rate. Solvent $50 \%$. Acetic acid (v/v).

\section{Discussion}

Absence of any effect of $\mathrm{Mn}$ (II) on the oxidation rate indicates that $\mathrm{Mn}$ (III) is the only active species. Mn(II) retards the oxidation effected by $\mathrm{Mn}$ (IV) due to the following equilibrium ${ }^{5,6}$.

$$
\mathrm{Mn}(\mathrm{IV})+\mathrm{Mn}(\mathrm{II}) \gtrless 2 \mathrm{Mn} \text { (III) . }
$$

It has been suggested recently ${ }^{7}$ that in strong sulphuric acid solutions Mn(III) exist as $\left[\mathrm{Mn}\left(\mathrm{HSO}_{4}\right)_{3}(\mathrm{OH})_{3}\right]^{3 \ominus}$ and this is probably the oxidising species.

The kinetics of the oxidation and enolisation reactions of methyl $n$-propyl ketone are quite dif-

5 T. J. Kemp and W. A. Waters, J. chem. Soc. [London] 1964, 339.

6 D. R. Rosseinsky, J. chem. Soc. [London] 1963, 1181. ferent. Enolisation is an acid catalysed reaction and is favoured by increase in the proportion of acetic acid in solvent, whereas the oxidation is independent of these variations. The rate of enolisation of methyl $n$-propyl ketone in $20 \%$ acetic acid solution, at $35^{\circ} \mathrm{C}$ is $3.31 \times 10^{-4} l$. mole $^{-1}$ sec. $^{-1}$, while the specific rate constant, $k$, for oxidation unter similar condition is $31.2 \times 10^{-4} l$. mole ${ }^{-1}$ sec. $^{-1}$. If enolisation was to precede oxidation, the oxidation rate in the limit could be equal to the rate of enolisation, but could never have exceeded it. This, therefore, clearly shows that oxidation of methyl $n$-propyl ketone by $\mathrm{Mn}$ (III) sulphate proceed by a direct attack on the keto-form.

The following mechanism may then be proposed. The first step is the rapid reversible formation of a complex between the ketone and manganese (III) sulphate complex, followed by the rate determining step involving a $\mathrm{C}-\mathrm{H}$ bond rupture yielding a radical. The radical is then oxidised by several fast steps.

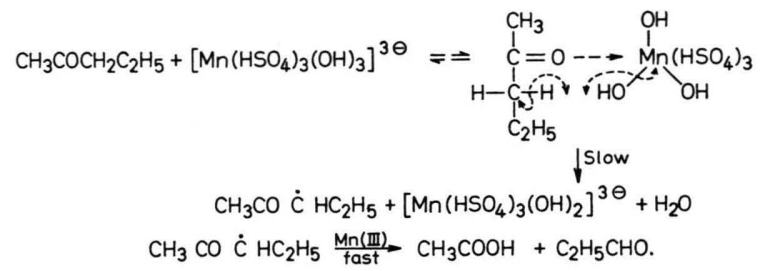

\section{Experimental}

Materials: Methyl $n$-propyl ketone (B.D.H.) was used after fractionation. Acetic acid (99.4\%, B.D.H.) was distilled over chromic acid. All other chemicals used were chemically pure.

Manganese (III) sulphate was prepared as described by VOGEL 8 .

Kinetic measurement: Reactions were carried out at $35^{\circ} \mathrm{C}\left( \pm 0.05^{\circ} \mathrm{C}\right)$ and in $20 \%$ acetic acid solvent unless mentioned otherwise. Concentration of the ketone was always in large excess to that of Mn(III). Sufficiently large excess of $\mathrm{Mn}$ (II) are added prevent disproportionation of $\mathrm{Mn}$ (III) to $\mathrm{Mn}(\mathrm{IV})$. The reaction were followed by quenching aliquots, withdrawn at known intervals of time in slight excess of $\mathrm{Fe}(\mathrm{II})$ and titrating the residual $\mathrm{Fe}(\mathrm{II})$ against $\mathrm{Ce}(\mathrm{IV})$ using ferroin as an indicator.

7 K. K. Banerji, P. Nath, and G. V. Bakore, Bull. chem. Soc. Japan 43, 2027 [1970].

8 A. I. VogeL, "A Text book of quantitative inorganic analysis”, Longmans Green \& Co., London 1964, p. 327. 